\title{
A expulsão da arte-verdade na República de Platão ou a problemática da percepção psíquica em torno dos mythoi
}

The expulsion of art-truth in Plato's Republic or the problematic of psychic perception around the mythoi

\author{
Luciano Coutinho
}

\section{RESUMO}

A expulsão do artista na República, de Platão, tornou-se muito famosa na História da Filosofia. Essa expulsão, no entanto, simboliza antes a condenação da percepção psíquica da realidade baseada nas imagens míticas como se fossem verdades. Nesse sentido, a expulsão está ligada à condenação da maneira literal com que os mythoi são seguidos pelos fieis. Tentaremos demonstrar, neste trabalho, portanto, o contexto em que a personagem Sócrates levanta essa problemática, para, por fim, verificarmos o que significa, de fato, essa expulsão. Assim, poderemos perceber como Platão reverte a problemática da expulsão com a proposta do melhoramento de percepção psíquica da realidade no final do diálogo.

Palavras-chave: Platão; República; CrençaVerdade; Arte-Verossimilhança; Expulsão da Crença-Verdade.

\begin{abstract}
The expulsion of the artist in Plato's Republic became very famous in the History of Philosophy. However, this expulsion symbolizes above all the condemnation of the psychic perception of reality, based on the mythical images as if they were truths. In this sense, expulsion is linked to condemnation in the literal way in which the mythoi are understood by the believers. Therefore, we will try to demonstrate, in this work, the context in which the character Socrates raises this problematic, in order to verify the real meaning of this expulsion. Thus, we can see how Plato reverses the problem of the expulsion by the proposal of improving the psychic perception of reality, at the end of the dialogue.
\end{abstract}

Keywords: Plato; Republic; Belief-Truth; ArtLikelihood; Expulsion to Belief-Truth.

Professor de Estética na Universidade de Brasília (UnB), Pós-Doutor em Filosofia Antiga pela Universidade Federal de Uberlândia (UFU), Doutor em Estudos Clássicos / Filosofia Antiga pela Universidade de Coimbra (UC), possui dois Mestrados, um em Filosofia, outro em Arquitetura e Urbanismo (com ênfase em Estética e Semiótica), ambos pela Universidade de Brasília (UnB). Atualmente desenvolve estágio Pós-Doutoral em “Medicina e Psicologia na Antiguidade" pela Universidade do Minho (UM), e em "Psicologia de Platão" pela Universidade Federal de Uberlândia 


\section{INTRODUÇÃO}

Tornou-se bastante famosa, em nossa História da Filosofia, a expulsão do artista na República de Platão. Se entendermos esta questão como mera dizimação da grande obra de arte na polis, estaríamos desprezando problemas mais importantes dispostos no diálogo em torno das crenças humanas.

É certo que grandes poetas como Homero são expulsos pela personagem Sócrates no livro segundo, mas compreender essa expulsão de maneira isolada do restante do diálogo seria um erro sem precedentes, embora bastante comum. É preciso, em alternativa, perceber como essa questão se conjuga com a teoria da percepção psíquica da realidade e do melhoramento da psyche humana.

Demonstrar que a psyche pode ser melhorada, e também a polis, é um projeto que Platão não abre mão em sua República. E isto está diretamente ligado ao problema das representações imagéticas entendidas como revelações divinas por parte dos cidadãos de uma polis. Nesse sentido, estamos diante da expressão mythos e não da expressão “arte” (que ainda não existia na época de Platão).

No livro segundo, Sócrates propõe que o Estado deve vigiar os fazedores de mythos, para que os mythoi, por sua vez, possam moldar as psychai dos cidadãos. Mas esta é uma postura que a própria personagem abandona a partir dos livros sexto e sétimo, defendendo que a mudança da psyche deve ser feita de dentro para fora e não de fora para dentro, conforme sustenta na primeira metade do diálogo.
Nesse sentido, a problemática abre-se para um contexto muito mais complexo, pois, ao condenar os poetas (em especial Homero e Hesíodo), Platão está, na verdade, a condenar a rasa capacidade perceptiva dos cidadãos, além, é claro, da postura do Estado ao aproveitar-se dessa rasa capacidade de percepção psíquica da realidade para manipular seus cidadãos. Assim, aquilo que deveria ser entendido esteticamente como obra de arte é entendido como revelação religiosa verdadeira. A obra de arte, nesse contexto, é lida e entendida literalmente pelos fieis. Significa dizer que a condenação empreendida no livro segundo aos poetas não é, de fato, uma condenação do artista e de sua obra de arte, mas antes da maneira como a obra de arte está a ser percebida pelos cidadãos.

Apresentaremos, portanto, como Platão, na República, problematiza a relação entre os paralelos mythos e crença / verossimilhança e verdade. Com isso, poderemos verificar que Platão nega e condena todo tipo de pretensão de verdade imposta à obra de arte, em outras palavras, todo tipo de leitura literal que coloca a obra de arte como uma manifestação revelada do divino. Para finalizar, veremos como Sócrates faz um elogia a percepção psíquica da realidade capaz de entender a grandeza de um mythos enquanto representação verossímil à própria psyche humana.

Para tanto, dividiremos este trabalho em quatro seções, em que buscaremos aprofundar esses apontamentos introdutórios: na primeira seção, apresentaremos como Platão elabora uma postura tirânica para sua personagem Sócrates, para, na segunda seção, demonstrarmos que esta postura tirânica é o fator fundamental para a expulsão da grande obra de arte no interior de 
uma polis, ao buscar, na verdade, condenar a baixa capacidade perceptiva psíquica de um mythos; na terceira seção, apresentaremos como Platão faz sua personagem mudar sua psyche, abandonando sua postura tirânica e aderindo a uma postura filosófica, para, na quarta e última seção, demonstrarmos como a personagem Sócrates altera sua visão acerca da educação dos cidadãos, possibilitando, assim, a permanência da grande obra de arte em uma polis baseada em uma constituição filosófica.

\section{1- A tiRANia de Sócrates}

\section{A personagem Sócrates passa por uma} dramática caminhada filosófica na República de Platão. Seu drama se estende desde uma posição tirânica, na primeira metade do diálogo, até uma posição filosófica na segunda metade. ${ }^{1}$

No início do diálogo, Sócrates apresenta-se como um iniciando em filosofia, que arrisca, reflete e comete excessos como qualquer iniciando, mas, a fim de superar as diversas

1 Para aprofundamento dessa questão, indicamos a leitura da Tese Doutoral intitulada Katabasis e psyche em Platão, de Coutinho (2015, pp. 279-296). Cf. também Fialho (2012) que, embora de maneira mais geral, trata a República como um drama, ou quase um drama.

2 Cf. Voegelin (1986, pp. 108-115).

3 Apresentei detalhadamente tal questão no capítulo intitulado "O drama de katabasis na República de Platão: considerações em torno da Katéßฺv (R. 1, 327a1)" (COUTINHO, 2017).

4 "può essere ottenuta solo attraverso il confronto, l'inchiesta, il lavoro dialettico che devono aver luogo pazientemente nel contatto con le Zone 'infere' della cità, $i$ suoi strati social, le sue tradizioni culturali, i suoi conflitti politico-ideologici" (VEGETTI, 2010, pp. 102).

5 понтń (R. 1, 327a4).

6 Cf. República (1, 330d8). corrupções constituintes de uma polis, assume uma postura tirânica. No final do diálogo, ele assume o papel de filósofo, como quem demonstra que apenas a filosofia pode superar a tirania (o tipo de constituição mais corrupto e desarmônico que um Estado pode assumir).

A descida de Sócrates ao Pireu, um tipo de Hades-social ${ }^{2}$, recorre a uma imagem mítica, catabática, que sugere iniciação. Neste caso, todavia, não se trata de uma iniciação mistérica, que recorre à magia, mas sim a um ritual filosófico, que recorre ao confronto com a psyche humana. ${ }^{3}$ É nesse sentido que Sócrates desce ao Pireu e, como iniciando, busca conhecer os princípios que regem as realidades psíquicas dos cidadãos de estratos sociais inferiores: esse conhecimento, no entanto, não se dá por meio de revelação divina, mas antes "por meio do confronto, da investigação, do trabalho dialético que deve ocorrer pacientemente com as Zonas 'inferiores' da cidade, com seus estratos sociais, com suas tradições culturais, com seus conflitos políticoideológicos"4, e, principalmente, com questões relacionadas às crenças.

Nessa descida, a personagem Sócrates, deparase, já no início da trama, com questões relacionadas à baixa capacidade perceptiva da realidade por parte daqueles que estão no contexto da "procissão" no Pireu. O que é antes um teatro de sombras é percebido pelos praticantes religiosos como verdades. Tais imagens direcionam a vida psíquica dos observadores que nelas creem: um exemplo disso é o do velho Céfalo que discute com Sócrates os pagamentos, no Hades, dos crimes cometidos em vida ${ }^{6}$. O Hades não é propriamente o problema para Sócrates, a 
conveniência de se preocupar com os pagamentos dos crimes cometidos em vida apenas na velhice e acreditar que rituais mágicos podem purificar um iniciado de seus crimes são, para Sócrates, os problemas.

O Hades se torna o castigo (como um pano de fundo) para a discussão da vida justa na vida presente, tanto que Sócrates acaba sua caminhada, no livro décimo, com o relato de Er: uma (re)criação mítica de Platão da tradição órfica que sugere, ao contrário do orfismo, o hábito de vida como determinante dos destinos da psyche humana. Portanto, o Hades deve ser antes visto como uma representação do castigo de ter de viver com o caráter que lhe é próprio, e, em função deste caráter, pagar ou gozar pelas próprias ações. $^{7}$

No anseio de combater essa ignorância, em que as psychai tornam-se prisioneiras das imagens que elegem como verdadeiras no teatro de sombras, a personagem Sócrates procura combater com tirania a tirania da ignorância e da desarmonia psíquica dos cidadãos.

A psyche torna-se tirânica, quando encontra-se em completa desarmonia entre suas partes, causando a si própria a maior das cegueiras: aquela em que a parte racional da psyche é subjugada pelas outras duas partes, e pela violência procura manter caminho fértil para as conveniências dos desejos.

Platão, na República, elabora a teoria da tripartição da psyche, e sustenta que ela é constituída por uma parte "concupiscente" uma parte "irascível”" e por uma parte "racional"10. A tirania psíquica, para fazer alusão à teoria da constituição tirânica, seria determinada pela soberania das outras duas partes da psyche, de onde nasce todo sentimento de permissividade pela parte concupiscente, e de onde nasce o instinto de violência pela parte irascível. Esta parte, a irascível, garante 0 sucesso daquela, a concupiscente.

É tentando medir força com esse estado conveniente de ignorância e de tirania da psyche humana que a personagem Sócrates age, embora sem perceber, tiranicamente. Embora a ação de Sócrates tenha as melhores intenções para o bem coletivo do Estado, sua posição inicial é extremamente tirânica, e, por si, prejudicial como um todo. Sócrates chega, na primeira metade da República, a legislar até mesmo sobre as festas para encontros de casais e a quantidade de matrimônios que os governantes deveriam indicar. ${ }^{11}$ Este nível de Eugenia Platão, por exemplo, foi interpretado pelos Nazistas na Alemanha da Segunda Guerra Mundial como um legítimo e forte aliado filosófico. ${ }^{12}$ Mas não podemos divorciar este

7 Cf. República (10, 614bss)

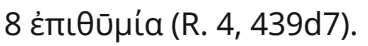

9 Өūjós (R. 2, 439e3); 3).

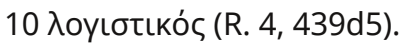

11Cf. República (5, 459e-460a). Indicamos a leitura do capítulo "A eugenia platónica: um ensaio prudencial", de Curado (2017), que, embora seja focado apenas na postura tirânica de Sócrates e acabe desprezando a mudança de sua postura no contexto geral da República, apresenta uma bela leitura da postura tirânica da personagem. 12 Este tipo de problema de interpretação é associado por Marino (2013) como um problema de "Metodologia da pesquisa em Estudos Clássicos", baseado, por sua vez, na celebre obra La nascita della filosofia vista dai Greci, de Casertano (2007), que sustenta a necessidade de se compreender o texto grego a partir de seu contexto, evitando, assim, radicalismos anacrônicos divorciados do próprio contexto cultural grego e do contexto da própria obra em questão. 
primeiro Sócrates do segundo Sócrates, como se Platão não tivesse escrito um drama com personagens e com uma trama em evolução.

Em sua teoria sobre os tipos de constituição de um Estado, a "tirania"13 é colocada como sendo a consequência inevitável da "democracia"14. Esta é corrupta porque se baseia em níveis de favorecimento não meritocráticos causados pela desarmonia entre as partes que a constitui. É dessa constituição democrática, enferma politicamente, que nasce a tirania. É do próprio povo que nasce o tirano; é do povo que ele recebe seu poder; mas é o próprio povo que ele aniquila. A democracia já é a desarmonia do Estado em sentido destrutivo, uma vez que as partes lutam umas contra as outras, da mesma maneira que uma enfermidade se instaura no soma por causa da desarmonia da psyche. ${ }^{15} \mathrm{~A}$ tirania, por sua vez, é o estágio mais degradado dessa enfermidade política.

Platão entende, não contra os mythoi, que este estado de ignorância mítica fundamenta-se tanto na tirania do Estado, que educa seus cidadãos para serem ignorantes, quanto na tirania das psychai, que são ignorantes porque estão regidas pelas duas partes inferiores: a concupiscente, que é regida pelo desejo desenfreado, e a irascível, que busca garantir a satisfação dos desejos pela violência.

13 тŭpavveúw (R. 8, 545c3; 565d2).

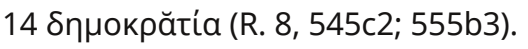

15 Faço aqui menção à teoria psicossomática que desenvolvi de modo mais amplo na Dissertação de Mestrado, na Tese Doutoral e no artigo recentemente aceito para publicação na Revista Educação e Filosofia da Universidade Federal de Uberlândia.
Platão percebe que o grande mythos tem uma imensa capacidade de sintonizar-se com a psyche humana; e este é o princípio que o Estado utiliza para manter as psychai em profunda ignorância. Isto ocorre quando um mythos é entendido como revelação religiosa e não como verossimilhança representativa a questões profundas da psyche humana. Nesse sentido, aquilo que poderia proporcionar (auto)conhecimento acaba por proporcionar ignorância. Ou seja, se entendido como verossimilhança representativa, um mythos pode levar as psychai para um grau de (auto)conhecimento elevado, mas, se entendido como revelação religiosa, pode levá-las a mais completa cegueira. É com essa descoberta que a personagem Sócrates defende, no livro segundo, a ideia de que o Estado deveria vigiar os fazedores de mythos e proibir a circulação dos mythoi de grande impacto psíquico, para evitar que as psychai, em suas ignorâncias, entendam os mythoi de maneira literal e acreditem em suas imagens de superfícies como se fossem verdades reveladas.

A qualidade representativa de uma imagem mítica, segundo esta teoria, estaria diretamente ligada ao seu impacto na psyche humana.

Portanto, quanto maior a qualidade representativa, maior o risco para um Estado regido pela ignorância, uma vez que tanto Estado quanto cidadãos irão sintonizar-se com o mythos por suas imagens literais de superfície. Nesse sentido, o mythos de excelência estética, para esse Sócrates tirânico, corrompe a psyche humana porque sua qualidade é tal que o observador ignorante passa a dar-lhe crédito de imagem-verdade. 
A ironia é que Platão elabora esse caráter tirânico em sua personagem Sócrates para denunciar, por um lado, a tirania dos Estados regidos pelas supostas revelações míticas - a própria Atenas de Platão parece se enquadrar nessa falida constituição que se diz democrática, mas que já evoluiu para a tirania (basta lembrarmos que Sócrates teria sido acusado de corromper o Estado com seu ateísmo, e, por isso, é condenado à morte). Se levarmos a imagem a sério, somos obrigados a perceber que a Atenas dessa época é regida não pelo povo, mas pelas crenças religiosas do povo. Por outro lado, Platão denuncia ainda que o exercício filosófico tende (pela desarmonia da psyche do iniciando) à tirania, uma vez que, quando alcançamos um conhecimento, temos a tendência de entendê-lo como verdade última, e passamos a impô-lo aos outros.

Assim, a intenção de Sócrates é boa ao querer combater a tirania psíquica, tanto em nível estatal quanto em nível individual, mas como costumamos dizer aqui no Brasil (e brinco com uma analogia anacrônica): "de boas intenções, o inferno está cheio”. A maior mensagem de Platão, para essa pseudo-bondade socrática, é demonstrar que não se pode combater tirania com tirania.

Sócrates ainda não está filosoficamente preparado nesta primeira metade do drama dialógico, por isso assume a postura de manipular os cidadãos com mythoi menores, fáceis de manipular, com pouca qualidade de verossimilhança representativa à psyche humana. Afinal, ele propõe a substituição de um estado de ignorância vivido pelos fieis crentes (que acreditam nos mythoi como verdades) por um estado de ignorância estatal que atesta sua incompetência quanto à educação de seus cidadãos.
Mythos e Estado se coincidem em tamanho nesse tipo de constituição: os dois são menores e não têm valor pelo que se propõem a ser.

\section{2- A EXPULSÃO DA ARTE-VERDADE}

\section{A primeira questão ligada a essa} problemática é o fato da pouca compreensão que temos, em nossos dias, acerca da expressão "arte" direcionada à Grécia Clássica. Nessa época, a expressão "arte” não existia. Isto não quer dizer que não possamos utilizar a expressão "arte" contextualizada no período Clássico (entendemos esta questão como um anacronismo aceitável, mas que temos de ter muito cuidado ao fazêlo na República).

No diálogo, a personagem Sócrates expulsa os mitólogos e propõe que se vigie os $\mu$ טөолоเоíi ${ }^{16}$ (mythopoio: "fazedores de mythos"). Minha primeira consideração a esse respeito é que a sugestão de Sócrates de proibir mitólogos como Homero e Hesíodo, e de sugerir que se vigie ${ }^{17}$ os "fazedores de mythos", permite-nos dizer que apenas os grandes mitólogos devem ser expulsos de sua polis tirânica. Minha segunda consideração é que, nos nossos dias, entendemos Homero e Hesíodo como textos literários - isto é equivalente a entendermos a Bíblia (tanto a parte judaica quanto a parte cristã) como literatura. Para nosso conhecimento, Platão, de fato, entendia esses textos religiosos de sua época como poéticos. Platão dá provas disso ao longo do diálogo, ao

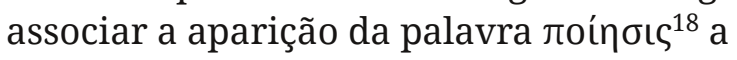

16 República $(2,377 \mathrm{~b} 11)$.

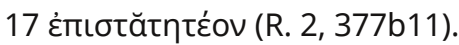

18 República $(3,393 d 1)$. 


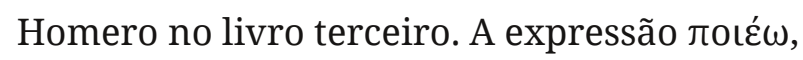
em grego antigo, significa "fazer", e o nominativo feminino roínбıৎ significa “composição poética”.

A expressão $\mu \overline{\operatorname{v} \theta 0 \pi о o ́} \varsigma$ (mythopoios), portanto, indica "fazedores de mythos" no sentido de "compositores de mythos". Uma expressão que nos ajudará a compreender essa questão está, na alegoria da Caverna, livro sétimo, utilizada por Sócrates para indicar o espetáculo maravilhoso criado pelas sombras na parede da

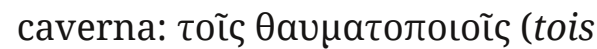

thaumatopoios: “os que realizam maravilhas") ${ }^{19}$.

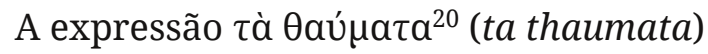
significa "as coisas maravilhosas", no mesmo sentido que guarda nossa teoria literária ${ }^{21}$. Portanto, tois thaumatopoios são "os que realizam maravilhas", porque fazem "as coisas maravilhosas”; em outras palavras, são "os ilusionistas”. Nesse sentido, o thaumatopoios é aquele que, na alegoria da Caverna, projeta sombras na parede da caverna, assim como o mythopoios, no diálogo como um todo, é aquele que cria histórias míticas, que funcionam como sombras para os que têm percepção rasa da realidade, e como verossimilhança para os que têm melhor percepção da realidade.

19 República $(7,514 b 5)$.

20 República $(7,514 b 6)$.

21 Para Todorov, não há limites definido para o “maravilhoso puro"; a característica do maravilhoso não é uma atitude, para os acontecimentos relatados, mas a natureza mesma desses acontecimentos (Todorov 1999: 30).

22 "discours public, rumeur, nouvelle, dialogue, conseil, objet du discours ou du la conversation, fable, récit non historique, mythe, récit fabuleux, conte, faire des contes, dire des mensonges, apologue" (BAILLY, 1935).
Outra consideração que merece nossa atenção nesta seção é o fato de a expressão $\mu$ ṽ $\theta$ o (mythos) poder significar muitas coisas para o grego antigo: "discurso público, rumor, narrativa, diálogo, conselho, objeto de discurso ou de conversação, fábula, relato não histórico, mito, relato fabuloso, conto, faz de contas, mentiras, apologia”22. O fato é que mythos não significa o que entendemos atualmente por "mito" - mythos pode ser também "mito". No contexto da República, percebemos que Sócrates se refere ao fazedor de mythos como aquele que cria histórias ficcionais, que, pela crença, acabam por ser entendidas como histórias não ficcionais, verdadeiras.

A temática da expulsão do artista na República é, de fato, bastante conhecida de nossa história da filosofia. O que é pouco conhecido, no entanto, é o contexto dessa expulsão, e isto levanos a certa ignorância da causa (no sentido que guarda a lógica interna da trama) que leva a personagem Sócrates a sugerir a expulsão de poetas como Homero.

Platão, na República, problematiza a relação entre os paralelos mythos e crença / verossimilhança e verdade. Com isto, podemos verificar que Platão, na verdade, nega e condena todo tipo de pretensão de verdade imposta às representações ficcionais, ao passo que elogia a percepção desse tipo de representação como verossimilhança à psyche humana. O fato é que Sócrates não expulsa propriamente os artistas, mas antes os fazedores de mythos. Mas, como falamos anteriormente, Platão entende que os mythoi são antes verossimlhanças representativas à psyche humana. Sua contenda, nesse sentido, não é ontológica: Platão não expulsa os mythoi 
que considera falsos para substituí-los por outros que considera verdadeiros. A questão é epistemológica, no sentido de condenar uma atitude perceptiva fraca de entender os mythoi como verdades e não como verossimilhança representativa a questões ligadas à psyche humana, em primeiro lugar, e, em segundo lugar, no sentido de verificar quais mythoi seriam mais verossimilhantes à psyche humana. Para isso, entretanto, Platão faz duas críticas em uma mesma passagem: condena a ignorância psíquica no interior do Estado e chama atenção para o cuidado de os iniciandos em filosofia não agirem com tirania diante das tiranias encontradas em suas caminhadas.

Assim, a grande obra de arte, capaz de sintonizar-se com a psyche humana, é proibida pelo primeiro Sócrates exatamente porque seus observadores destituem-na de seu caráter estético, e entendem-na como verdade, esvaziando-a com leituras literais.

Platão, nesse contexto, chama atenção para o fato de que a psyche humana encontra-se em completa ignorância por não conseguir perceber que um mythos é antes uma imagem estética que deve ser entendida como representação, e que, se entendido literalmente, assume papel de "sombra" e passa a ser única verdade possível ao observador. Entendida assim, a obra de arte torna-se um engodo para o indivíduo, que permanece em sua própria caverna psíquica como um prisioneiro. Toda a polis sofre as consequências dessa ignorância, ela própria é ignorante por permitir tal coisa; ficam em desarmonia e corrupção as psychai e a polis.
Platão faz sua personagem Sócrates (em sua postura tirânica) sustentar que o Estado deve "moldar a própria psyche com os mythoi muito mais do que o corpo com as mãos"23, frase de Sócrates que mescla preocupação com bem coletivo e ação tirânica (para buscar alcançar esse bem), trocando seis por meia dúzia e substituindo uma cegueira por outra. Dito de outra maneira, Sócrates propõe a substituição da cegueira psíquica dos observadores que acreditam literalmente nos mythoi por uma cegueira estatal que pretende proibir a circulação das grandes imagens artísticas e divulgar imagens manipuladas, fracas, que buscariam moldar as psychai humanas com ideias aprovadas e controladas previamente pelo Estado. Outra vez uma brilhante ironia de Platão: mesmo as reflexões filosóficas tendem a assumir um caráter tirânico. Por isso o verdadeiro filósofo precisa duvidar até mesmo de suas próprias proposições e verdades. Sempre.

O problema da expulsão do artista, portanto, está antes ligado ao problema da percepção psíquica da realidade, ou melhor, da falta de percepção psíquica da realidade. A postura de expulsar o grande artista por parte da personagem Sócrates, na primeira metade do diálogo, simboliza, na verdade, o intuito de Platão de chamar atenção, em primeiro lugar, para o fato de que a grande obra de arte carrega consigo uma forte verossimilhança à psyche humana, por isso é capaz de ser creditada religiosamente como revelação, e, em segundo lugar, para o fato de que, se entendida literalmente, torna-se um risco para a harmonia do Estado. 
Platão propõe, nesse impasse, uma mudança de postura de sua personagem Sócrates, que passa a propor uma educação que busca erradicar da polis níveis primários e rasos de percepção da realidade. Para isso, precisa erradicar a tirania. É nesse novo espírito que a personagem Sócrates passa para um outro nível de percepção da realidade e supera sua postura tirânica, assumindo uma postura filosófica, que busca a educação dos cidadãos de dentro da psyche para fora, e não de fora para dentro (como uma imposição estatal). Ele, finalmente, deixa de combater tirania com tirania.

\section{3- A FILOSOFIA SUPERA A TIRANIA}

Na segunda metade da República, a personagem Sócrates finalmente compreende que uma polis só pode ser melhorada, se as psychai de seus cidadãos forem também melhoradas. Melhorar, nesse contexto, significa alcançar a harmonia interior.

A harmonia interior está associada à teoria da tripartição da psyche (que vimos

anteriormente, mas que vamos, aqui, retomar). Em outras palavras, harmonia psíquica equivale à temperança da psyche. Isto significa que as partes concupiscente, irascível e racional

24 Comungamos com Vegetti a ideia de que a expressão tò áyaӨòv é melhor traduzida por "o bom" e não por "o bem". A justificativa apresentada está no fato de que a expressão é sempre utilizada por Platão como "un aggettivo neutro sostantivato" (VEGETTI, 2003, p. 253, nota 1). Em Língua Portuguesa, chamamos isso de derivação imprópria: a transformação de uma classe morfológica em outra como, por exemplo, um verbo ou um adjetivo substantivado.

25 Cf. República (6, 508a4-508c2).

26 República $(7,515 c 6)$. estão operando para o bem comum da psyche como um todo.

A tese sustenta a ideia de que a parte racional deve exercer certa soberania sobre as outras duas partes. Utilizo a expressão "soberania" para indicar que razão deve dominar a ira e os desejos, e relativizo a ação de soberania com a expressão “certa” para deixar claro que não se trata de uma negação das outras duas partes, mas antes de uma reeducação das outras duas partes. A lógica interna da tese da tripartição da psyche sugere que a parte racional deve reeducar a parte irascível, a fim de que, com o auxílio desta última, possa direcionar os desejos da parte concupiscente.

Para que consiga harmonizar-se, a psyche humana precisa melhorar sua percepção da realidade. Mas como se dá esse processo, Platão responde no livro sexto com o paralelo entre o "sol" e o "bom" ${ }^{24}$. Nele, Sócrates sugere que "sol" está para a "visão" da mesma maneira que o "bom" está para o "intelecto"25. Assim, a percepção do plano visível dá-se pela "visão" que percebe a existência das coisas visíveis iluminadas pelo "sol”. A percepção do plano inteligível dá-se pelo "intelecto" que percebe os inteligíveis iluminados pelo "bom”.

É, aliás, em uma das alegorias mais famosas da História da Filosofia que Platão nos apresenta uma figura fundamental para o contexto do diálogo, talvez o único da República que age segundo esse "bom”: o "alguém” $(\tau \iota \varsigma)^{26}$ que solta o prisioneiro no interior da Caverna. Este alguém assume, na alegoria, o papel de um filósofo, que, sem pretender recompensas pessoais, age quase que invisivelmente ao praticar uma boa ação. A brincadeira estética é 
que, na Odisseia de Homero, Ulisses denomina-

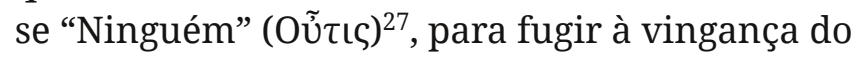
ciclope Polifemo depois de cegá-lo. O fato é que

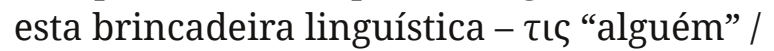
Oũ̃ıৎ “ninguém” - é já uma resposta sutil para a hipótese de Glauco, levantada no livro segundo com o mythos de "um antepassado de Giges" (R. $2,359 \mathrm{~d} 1)^{28}$, ao sugerir que, diante de um anel ${ }^{29}$ capaz de invisibilizar o soma, a psyche humana ficaria livre para satisfazer seus desejos mais permissivos. ${ }^{30}$

Assim como a "visão" não pode focar diretamente o "sol”, por limitações fisiológicas, também o "intelecto" não pode focar diretamente o "bom”, por limitações psíquicas. Platão sugere, com isso, que da mesma maneira que o soma pode apenas perceber a existência dos objetos visíveis, que são iluminados pelo sol, a psyche pode apenas perceber a existência dos inteligíveis, que são iluminados pelo "bom".

O sol não dá existência aos objetos visíveis, mas torna possível ao soma, ou melhor, às vistas, perceber suas existências. Dito de outra maneira, o sol ilumina os objetos visíveis para que a visão possa perceber a existência desses objetos visíveis, assim como o "bom” não dá existência aos inteligíveis, mas torna possível à psyche, ou melhor, ao intelecto, perceber suas existências. O "bom" ilumina os inteligíveis para que o intelecto possa perceber a existência deles. O fato é que, percebendo a existência da ideia de "bom" e sendo iluminado por essa ideia, a psyche busca ser ela própria boa. Tratase, portanto, de buscar ser melhor.

É com esse conhecimento que Sócrates supera sua postura tirânica. E é com a analogia entre 0 "sol" e o "bom", no livro sexto, que Sócrates sugere um método para que a psyche se torne melhor: buscar ser iluminada pela ideia de "bom”. É pelo "bom” que a psyche humana consegue, segundo sugere Sócrates, buscar a verossimilhança na multiplicidade das coisas, e esta verossimilhança está ligada à ideia de "bom”, uma vez que a busca do conhecimento filosófico não se torna mera busca do conhecimento técnico.

Platão faz uma relação entre a multidão no interior de uma polis, constituída pela classe dos técnicos (os artesãos) e a parte mais expressiva da psyche: a concupiscente, que é "muito maior" ${ }^{31}$ que as outras duas partes, afirma

27 Odisseia $(9$, v. 366).

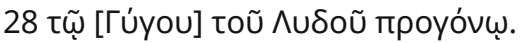

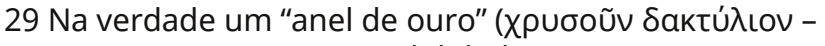
R. 2, 359e1) que causa invisibilidade.

30 Esta é uma das conclusões, dentre muitas, da pesquisa Pós-Doutoral que realizei na Universidade Federal de Uberlândia - UFU, divulgada pela primeira vez em uma Conferência a convite da Cátedra Unesco Archai - UnB, pela segunda vez em uma Conferência a convite do PPG/FIL UFU e, pela terceira vez neste III Simpósio de Estética, Hermêutica e Semiótica: Arte e Verdade, realizado na UnB, em debate dialogado com a conferência do Professor Flávio René Kothe, mas publicada, com muito prazer, pela primeira vez nesta Revista Estética e Semiótica (RES) da UnB. A motivação inicial para verificar mais de perto essa questão foi a originalidade do tema: o fato de não haver, nos comentadores da República, um direcionamento aprofundado para esta figura tão enigmática e quase invisível da alegoria da Caverna que liberta o prisioneiro. Também me chamou a atenção o fato de o tema da invisibilidade estar presente no diálogo como um todo. Outro fato, que pude verificar mais de perto na Tese Doutoral intitulada Katabasis e psyche em Platão, são as recriações de Platão de vários mythoi da tradição que dialogam entre si em seus diálogos e fazem intertextos com os próprios mythoi da tradição. Estes foram pontos cruciais que me levaram a propor o "alguém" da Caverna como um intertexto com o “Ninguém” da Odisséia de Homero.

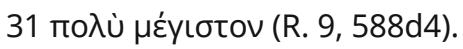


Sócrates. Regida pela parte concupiscente, a multidão jamais poderia se tornar filósofa ${ }^{32}$. Se educadas, segundo os princípios propostos pelo Sócrates da segunda metade da República, as psychai dos técnicos tornar-se-iam positivamente aptas para os negócios ${ }^{33}$, sem se darem, no entanto, à libertinagem de seus desejos desenfreados e permissivos.

Precisamos nos lembrar que a multidão a que se refere Sócrates é representada pelos demoi. A

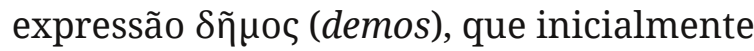
significa "distrito/um pedaço de terra" assume posteriormente o significado político de "povo". Esta é a expressão que dá origem à palavra

32 Cf. República $(6,494 a 4)$.

33 Cf. República (R. 9, 561d).

34 Ferreira faz um resumo bastante esclarecedor sobre a associação da democracia ao povo: “Democracia é assim o 'governo pelo demos', povo. Mas o que era o dêmos no apogeu da democracia ateniense, no século $V$ a.C.? Um passo dos Memoráveis de Xenofonte procura definir o seu conteúdo social para o comum das pessoas. Sócrates dialoga com Eutidemo e pergunta-lhe se considera possível saber o que é a democracia sem ter a noção do que é o dêmos. O interlocutor responde negativamente e, ao ser interrogado sobre o sentido que atribui a tal termo, reponde que 'são os pobres, dentre os cidadãos' (4.2.37). Elucidativa, esta definição demonstra com toda a evidência que, no pensar comum, os pobres constituem a base e a força de tal regime; deixa perceber, por outro lado, uma oposição surda e certos laivos de desprezo por esse povo" (FERREIRA, 2004 p. 76). Para Platão, o problema da democracia não é que o povo seja pobre materialmente, até porque nela o povo está apto a buscar a riqueza, mas porque o povo tem, via de regra, um tipo de psyche desarmônica.

35 íovoutкó $(8,561 \mathrm{e} 1)$.

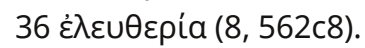

37 Cf. República $(9,561 d)$.

38 Podemos perceber esta economia de diferenciação entre os níveis de "confiança" e de "assimilação" no mythos da autoctonia (R. 3, 415a), em que Platão recria, também economicamente, o mythos das idades de "democracia”. ${ }^{34}$ A analogia entre a psyche de um técnico (artesão) e a democracia, na República, está na ideia de que esta última é estabelecida por uma desarmonia entre as três classes da polis (nomeadamente: a classe dos técnicos, a dos guerreiros e a dos governantes) e aquela, a psyche de um técnico (artesão), é estabelecida pela desarmonia entre suas três partes (a concupiscente, a irascível e a racional).

A democracia, na República, é enquadrada na hierarquia das constituições como a segunda pior; melhor apenas que a tirania, que nasce da própria democracia. Esta representa o desequilíbrio porque tudo é permitido, liberdade é confundida com libertinagem, e todos os desejos dos mais eruditos aos mais banais podem ser satisfeitos. A psyche de um técnico (artesão) é análoga à democracia na medida em que suas três partes brigam entre si. Os artesãos são amantes da "igualdade" 35 e da "liberdade" 36 , e, por isso, sentem-se iguais uns aos outros (sustenta o segundo Sócrates), e, assim, fazem o que querem. Este tipo de psyche às vezes se embriaga, outras vezes bebe água e emagrece; às vezes faz ginástica, outras vezes é ocioso; às vezes se dedica à filosofia, outras sobe e diz o que quer na tribuna; uns dias inveja os militares e lhes apoia, outros inveja os negociantes e volta-se para os negócios ${ }^{37}$.

A classe dos técnicos (os artesãos) alcançariam apenas a percepção dada pela

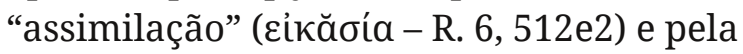
"confiança” ( expressões fazem referência direta aos dois níveis mais fracos de percepção psíquica da realidade na imagem da Linha, ainda no livro sexto. ${ }^{38} \mathrm{~A}$ mais fraca de todas, associada à “assimilação”, é o tipo de percepção 
apresentado no primeiro seguimento da Linha, aquele que vê apenas sombras (referência paralela à realidade dos prisioneiros da alegoria da Caverna no livro sétimo), e como se fossem verdades apenas assimila as sombras. A segunda mais fraca, associada à “confiança”, é o tipo de percepção apresentado no segundo seguimento da Linha, aquele que vê, para além das sombras, os objetos originários (referência paralela à realidade dos passantes no interior da Caverna na alegoria do livro sétimo), mas agora, pela comparação, confia que alcançou a verdade e o que antes via como verdades eram mentiras, ou seja, sombras. Estes dois tipos de percepção da realidade são os mais rasos, porque estão ligados apenas à percepção da realidade visível do cosmos.

É nesse sentido que o papel do Estado não é, portanto, manipular as psychai, mas antes direcioná-las a uma reeducação psíquica, cuja percepção da realidade possa alcançar as formas inteligíveis. E o papel de cada psyche, por sua vez, é buscar melhorar-se a si própria, permitindo-se direcionar cada vez mais pelo "bom", que cabe lembrar não é determinado pelo Estado, mas percebido pela psyche a partir do melhoramento de sua percepção. Para que isto ocorra, cada psyche precisa buscar comparar os objetos visíveis, para que destes se revelem as formas, que, na imagem da Linha, estão no terceiro seguimento, associadas ao "entendimento" ( $\delta$ เávoı́a-R. 6, $511 \mathrm{~d} 8$ ), e no quarto, associadas à “inteligência” (vónoıৎ-R. 6, 511d8).

Esta é a prova de que, na República, a expulsão do artista é antes uma questão relacionada à percepção da psyche, enquanto "assimilação" e "confiança”, da realidade em torno dos mythoi da tradição. Isto não quer dizer que a personagem Sócrates seja um ateu a sustentar que a crença deva ser extirpada da polis - cabe lembrar, por exemplo, que no Apologia, diálogo de Platão que trata dos argumentos da condenação de Sócrates à morte, a personagem chama atenção para o fato de ter crença em outras instâncias, mostrando outra perspectiva da realidade. Sócrates é apresentado, no diálogo, como um cidadão que examina as crenças e as tradições religiosas de sua polis, e isto não significa que ele seja ateu, mas antes que assume crenças diferentes. E, ao assumi-las, investiga-as e admiti-as como apenas verossímeis e não como verdades. Um exemplo disso, na República, está no livro décimo com o relato de Er.

\section{4- O ELOGIO À GRANDE OBRA DE ARTE}

O relato de Er, no livro décimo, é apresentado como um "espetáculo"39. Espetáculo que é descrito como "digno de piedade", "risível” e "maravilhoso"40. Esta terminologia de impacto teatral auxilia não apenas na compreensão do diálogo como um drama, mas também na ideia de que o relato de Er, uma (re)criação de Platão baseada em elementos da tradição órfica, é antes uma representação estética que trata de questões mais verossímeis à psyche humana.

\footnotetext{
Hesíodo (Trab. vv. 106-200) ao colocar no mesmo patamar a psyche de "ferro e de bronze", e separar apenas a psyche de "prata" e a psyche de "ouro", indicando, com isso, que a psyche de "ferro/bronze" está associada ao nível mais básico de percepção da realidade que coincide com aquela que se dá no nível do visível apenas, alcançada pela psyche do técnico (artesão). 39 t̀̀v $\theta \varepsilon ́ a v$ (R. 10, 619e6).

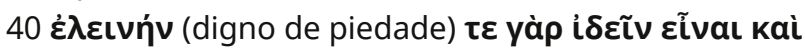

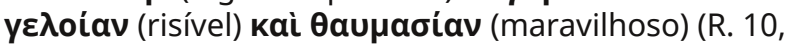
620a1-620a2).
} 
Assim, o mythos de Er é analisado como uma representação estética, como arte. A arte, nesse contexto, deixa de ser verdade para assumir papel de verossimilhança. Sócrates está no final de sua iniciação filosófica e termina sua caminhada refletindo acerca de uma polis regida por uma constituição filosófica. Nesta pretensa polis filosófica, a harmonia é instaurada pela temperança das psychai, que seriam (re)educadas de dentro para fora, e, por isso, não se deixariam manipular pelas imagens de superfície dos mythoi. Ao contrário, as psychai, nesse tipo de constituição, seriam direcionadas a buscar superar seus estados de “confiança” e de "assimilação" em relação à percepção psíquica da realidade, para

41 Todorov afirma que o fantástico é uma "vacilação comum ao leitor e ao personagem, que devem decidir se o que percebem provém ou não da 'realidade', tal como existe para a opinião corrente. Ao finalizar a história, o leitor, se o personagem não o tiver feito, toma entretanto uma decisão: opta por uma ou outra solução, saindo assim do fantástico. Se decidir que as leis da realidade ficam intactas e permitem explicar os fenômenos descritos, dizemos que a obra pertence a outro gênero: o estranho. Se, pelo contrário, decide que é necessário admitir novas leis da natureza mediante as quais o fenômeno pode ser explicado, entramos no gênero do maravilhoso" (Todorov 1999: 24). Esta indicativa de Todorov monstra-nos com clareza que um mesmo mythos pode ser concebido como representação estética ou como verdade revelada, tudo isto a depender se quem observa é um esteta ou um fiel.

42 кúkvos (R. 10, 620a4).

43 Diógenes Laércio relata uma imagem bastante elucidativa a esse respeito: “E conta-se que passava [Pitágoras] ao ser castigado um cachorrinho; sentiu piedade e pronunciou as seguintes palavras: 'Para de bater. Pois é a alma de um amigo meu, que reconheci ao ouvir os seus gemidos"' (21 B7 DK = D. L. Vitae 8, 36).

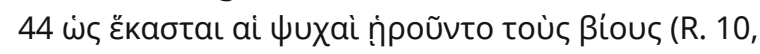
620a1).

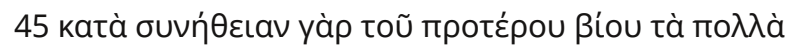

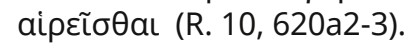

alcançarem o estado de percepção filosófica, reflexiva, e perceberem o que há por trás das imagens de superfícies. Os estados de “confiança” e de "assimilação" são colocados, no diálogo, como sinônimo de falta de reflexão, em outras palavras equivalem à crença cega nas imagens literais dos mythoi.

O "espetáculo" assume características do "fantástico"41, e prova disso é que Orfeu surge com a surpreendente escolha de ter sua alma transmigrada em um "cisne" 42 . Sabemos que esta é uma questão ligada também à ideia de transmigração pitagórica ${ }^{43}$, mas o fato é que, no relato de Er, a questão indica o cenário risível e maravilhoso.

Em meio a esse espetáculo maravilhoso e fantástico, Platão acrescenta um princípio que fundamenta toda sua filosofia: a responsabilidade de cada psyche acerca de seu próprio passado, presente e futuro.

Diferentemente da tradição órfica, que põe na mão dos deuses do julgamento a escolha da próxima reencarnação da psyche (contextualizada no relato como alma), na recriação platônica do orfismo (no relato de Er), Platão faz sua personagem Sócrates inverter o processo e colocar sob a responsabilidade de cada psyche sua decisão acerca da próxima reencarnação. Assim, no relato de Er, "a vida de cada uma das almas era escolhida" 44 pela própria psyche de acordo com o "intercurso dos hábitos da vida" 45 . Com isso, Platão pretende sustentar a noção de que a psyche é responsável pelo seu próprio destino, a partir de suas ações viciosas ou virtuosas.

Para Platão, não são as forças divinas que determinam o destino da psyche humana. A 
verossimilhança está, neste caso, na imagem de que a psyche passa por um tipo de julgamento, mas que, ao contrário da tradição órfica, dá-se por ela própria, na medida em que determina seus hábitos de vida, suas ações.

O momento mais importante para a felicidade, portanto, não é depois da morte, mas "enquanto ficarmos aqui" "46, ou seja, na vida presente. A expressão "aqui” é repetida duas vezes nas últimas quatro linhas do diálogo. Assim, enquanto a tradição órfica opera com a ideia de que devemos nos purificar (por meio ritual mágico) para a vida no além ou para as próximas reencarnações, o relato de Er (que é uma representação recriada da tradição órfica) apresenta uma preocupação com uma vida moral no aqui e agora (e os benefícios futuros disso serão apenas consequências de uma vida justa), não a partir de um ritual mágico, mas a partir de muito labor filosófico para o melhoramento da psyche.

Por um lado, na tradição órfica, a alma também é responsável por seu destino, mas numa perspectiva ritual que Platão não está disposto a aceitar. Num texto legitimamente órfico, é possível observar como o ritual, por si, seria capaz, segundo a crença órfica, de purificar um iniciado de seus crimes, fazendo-o passar ileso pelo julgamento no Hades: "Senhas:

Andrikepaidothyrson, Andrikepaidothyrson, Brimó, Brimó. Penetra na sacra pradeira, pois o iniciado está livre de castigo" (OF 493) ${ }^{47}$. A ideia de que os iniciados, com suas senhas e palavras mágicas, são capazes de purificar os crimes cometidos em vida, é definitivamente negado por Platão. Mas o filósofo não nega a ideia por trás disso de que a psyche é responsável por seu futuro, não porque sabe algumas palavras mágicas para purificar seus crimes, mas antes porque é capaz de, moralmente, observar-se melhor e buscando ser melhor, evitando os erros e os crimes.

Se levarmos a sério a imagem de que uma alma que teve uma vida justa teria condição de escolher uma transmigração mais acertada ${ }^{48}$, perceberemos que a conclusão de Sócrates sobre a imagem é exatamente o resultado reflexivo de sua iniciação filosófica, que o possibilitou, em nível psíquico, melhorar sua percepção realidade, tornando-se apto a verificar o que está por trás das imagens de superfície de um mythos. Embora ele próprio tenha suas crenças (no interior da trama que viveu enquanto personagem) e admita a transmigração da psyche (para ele uma entidade metafísica imortal equivalente à alma), ele admite também que se nos persuadirmos quanto ao mythos, será possível passarmos a salvo no julgamento e "não manchar a psyche" 49 , para "seguir o caminho para cima e praticar com sabedoria a justiça, de todas as maneiras" ${ }^{50}$. Persuadirmo-nos ${ }^{51}$, nesse contexto, significa antes refletir seus princípios e não seguir as imagens do mythos literalmente. $\mathrm{E}$ "seguir o caminho para cima" é metáfora para sairmos de nossas cavernas, prova disso é que todo o diálogo se passa sob uma imagem de katabasis no Pireu - cabe lembrar que Platão

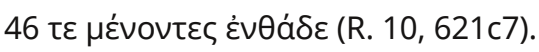

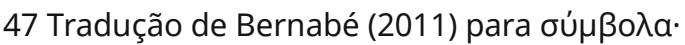

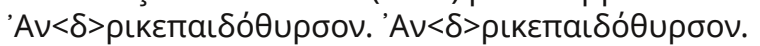

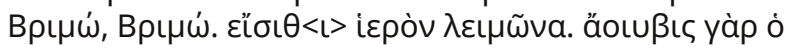

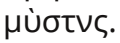
48 Cf. República (10, 614d-615a).

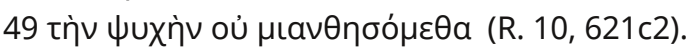

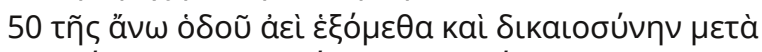

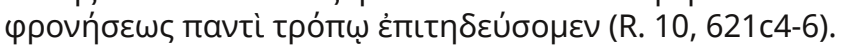




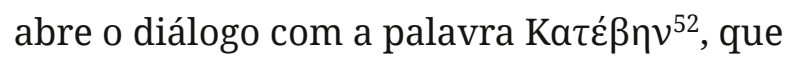
significa "desci", e que os interlocutores passam todo o diálogo imersos nessa descida, nessa caverna social.

Platão finaliza o diálogo com esta profunda reflexão filosófica sobre a tradição mítica de sua época, para demonstrar que os mythoi são antes representações estéticas, que devem ser compreendidas para além do que preservam em suas imagens de superfície.

Para Platão, a grande obra de arte, portanto, pode nos ensinar muito acerca da própria psyche humana. E apenas uma polis constituída pela filosofia pode evidenciar a grandeza da grande obra de arte, superando suas imagens de superfícies e buscando o há por trás dessas imagens.

\section{CONCLUSÃO}

A grande contribuição de Platão para a estética, na República, foi ter chamado atenção para o fato de que as imagens míticas devem ser antes entendidas como representações artísticas, que guardam certa verossimilhança a questões ligadas à psyche humana, propondo, assim, uma reeducação psíquica que refuta a prática de tais representações serem entendidas como revelações religiosas.

Para Platão, a grande obra de arte é aquela que guarda verossimilhança à psyche humana. Nesse sentido, Homero e Hesíodo não são

51 пвí $\theta \omega$ (R. 10, 621c1).

52 República (1, 327a1).

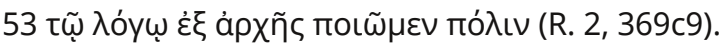

propriamente expulsos da "polis criada originalmente por palavras" 53 , mas antes são expulsos os tipos de constituição e de psyche que veem essas representações artísticas como revelações e verdades religiosas.

Para finalizar minhas considerações neste trabalho sinto-me à vontade para contextualizar o tema aqui proposto com a prática da profissão ligada à Arquitetura e ao Urbanismo.

Tenho repetido insistentemente para meus alunos de "Estética" deste semestre, que o Arquiteto e o Urbanista são antes de tudo Psicólogos. Ambos têm, em suas mãos, a responsabilidade de projetar edifícios e espaços: das casas aos monumentos; praças, escolas e todo tipo de construção em que somos passantes, convivas ou habitantes. Tudo influencia direta e/ ou indiretamente as relações psíquicas ligadas à nossa vida individual e pública nas cidades.

Gostaria de finalizar, portanto, este trabalho, com a invocação aos Arquitetos e aos Urbanistas a assumirem, com "bondade" (sem nenhum medo de ser chamado de idealista), a responsabilidade de serem psicólogos estéticos (mas práticos e funcionais) das psychai que solicitam suas habilidades e conhecimentos em nossas cidades.

\section{REFERÊNCIAS BIBLIOGRÁFICAS}

\section{Fontes primárias}

Laerzio, Diogene. Vite e dottrine dei più celebri filosofi. A cura di Giovanni Reale. Bompiani, Milano, 2005.

. Lives of Eminent Philosophers. R.D.

Hicks. Cambridge. Harvard University Press. 1972 (First published 1925). 
PLATÃO. A República. Trad. Maria Helena da Rocha-Pereira. Calouste Gulbenkian, Lisboa, 2005.

Republic in Plato in Twelve Volumes, Vols. $5 \& 6$ translated by Paul Shorey. Cambridge, MA, Harvard University Press, London, 1969.

Republic in Obras completas de Platón.

Trad. Patricio de Azcárate. Medina e Navarro, Madrid. 1871-1972. 1870, eBook 2008

. Republic in The Complete works.

Translated by Benjamin Jowett. Gutenberg project, England, 1870 (eBook 2008).

Repubblica in Tutti gli scritti. Traduzione di Giovanni Reale. Bompiani, Milano, 2008.

\section{Fontes secundárias}

BERNABÉ, Alberto. Platão e o orfismo - diálogo entre religião e filosofia. Annablume, São Paulo, 2011.

CASERTANO, Giovanni. La nascita della filosofia vista dai Greci. Con in Appendice: Può ancora Talete essere considerato il "primo filosofo"? Pistoia, Petite Plaisance, 2007.

COUTINHO, Luciano. "O drama de katabasis na República de Platão: considerações em torno da

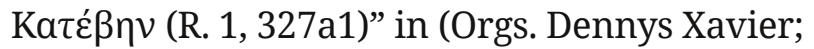
Coutinho Luciano; Curado, Manuel) Filosofia Antiga: reflexões da vida cósmica e da vida social. Tanto Mar Editores, Brasília, pp. 113-136, 2017.

Katabasis e psyche em Platão. Tese $304 \mathrm{f}$ (Doutorado em Estudos Clássicos / Filosofia Antiga). Instituto de Estudos Clássicos, Universidade de Coimbra, Coimbra, 2015.

CURADO, Manuel. "A eugenia platónica: um ensaio prudencial” in (Orgs. XAVIER, Dennys; COUTINHO, Luciano; CURADO, Manuel) Filosofia Antiga: reflexões acerca da vida cósmica e da vida social. Tanto Mar Editores, Brasília, 2017, pp. 187-246.

FERREIRA, José Ribeiro. A Grécia Antiga. Edições 70, Lisboa, 2004.

FIALHO, Maria do Céu. "A tragédia na Pólis perfeita” in Kléos, nºs 16/17, pp. 81-101, 2012/2013.

MARINO, Silvio. "Metodologia da pesquisa em Estudos Clássicos” in (Orgs. CORNELLI, Gabriele; COSTA, Gilmário) Estudos Clássicos II: História, Literatura e Arqueologia. Imprensa da Universidade de Coimbra / Annablume, Coimbra / São Paulo, 2013.

TODOROV, Tzvetan (1999). Introdução a literatura fantástica. Perspectiva, São Paulo.

VEGETTI, Mario. "Katabasis” in La Repubblica, vol. 1 (a cura di Mario Vegetti). Bibliopolis, Napoli, pp. 93-104, 2010.

“Megiston mathema: l'idea del 'buono' e le sue funzioni” in La Repubblica, vol. 5 (a cura di Mario Vegetti). Bibliopolis, Napoli, pp. 253-286, 2003.

VOEGELIN, Eric. Ordine e storia. La filosofia politica di Platone. Bologna, 1986.

\section{Dicionários}

BAILLY, Anatole. Dictionnaire Grec-Français. Paris, Hachette, 1950.

FREIRE, Antônio. Gramática Grega. Porto, Livraria Apostolado da Imprensa, 1971.

LIDDELL, H.G.; SCOTT, R.; JONES, H.S.; \& MCKENZIE, R. A Greek-English Lexicon, 9th edition, Oxford: Clarendon Press, 1940. 